\title{
TAXA DE NOVAS INFECÇÕES INTRAMAMÁRIAS EM VACAS LEITEIRAS, LIGADAS À PRECIPITAÇÃO PLUVIOMÉTRICA
}

\author{
PICOLI, Tony ${ }^{1}$ \\ ZANI, João Luiz² \\ PONZILACQUA, Bárbara ${ }^{3}$ \\ RIBEIRO, Maria Edi Rocha ${ }^{4}$ \\ FISCHER, Geferson ${ }^{5}$

\begin{abstract}
${ }^{1}$ Doutorando do Programa de Pós-Graduação em Veterinária/UFPel. ${ }^{2}$ Professor Adjunto do Departamento de Veterinária Preventiva/UFPel. ${ }^{3}$ Aluna de graduação em veterinária/UFPel. ${ }^{4}$ Pesquisadora EMBRAPA Clima
\end{abstract} \\ Temperado. ${ }^{5}$ Professor do Departamento de Veterinária Preventiva/UFpel.
}

\section{RESUMO}

\begin{abstract}
A melhoria na qualidade do leite vem sendo uma cobrança constante da sociedade e é determinada fundamentalmente pela forma como este é produzido. A qualidade microbiologia do leite é o fator mais preocupante à saúde pública e vários fatores podem influenciar nesta qualidade, sendo o principal deles o surgimento de mastites, que pode estar relacionado com condições ambientais como as chuvas. Este trabalho objetivou relacionar a taxa de novas infecções intramamárias com os índices de precipitação pluviométrica. Para tanto, foram coletadas 1917 amostras de leite para análise microbiológica e contagem de células somáticas (CCS) que foram relacionadas com o período de chuvas. Os agentes mais isolados foram Corynebacterium bovis, Staphylococcus spp. e Streptococcus spp. Entre os meses de maio-junho houveram novas infecções por $C$. bovis, Staphylococcus spp. e Streptococcus spp., respectivamente: 64, 20, 01 e precipitação pluviométrica de 54mm. Entre junho-julho: 43, 36, 05 e 49,8mm. Julho-agosto: 76, 42, 05 e 135mm. Agosto-setembro: 47, 18, 02 e 13,2mm. As correlações entre taxa de novas infecções e índice de chuvas foram as seguintes: $C$. bovis $(r=0,84 ; p=0,074)$, Staphylococcus spp. $(r=0,81 ; p=0,037)$ e Streptococcus spp. $(r=0,58 ; p=0,173)$. No período onde as precipitações pluviométricas foram maiores, as taxas de novas infecções também se elevaram. A CCS das amostras tiveram seus valores aumentados quando os números de novas infecções aumentaram. Com esses resultados, conclui-se que a precipitação pluviométrica interfere de forma negativa na produção leiteira, aumentando o número de novas infecções intramamárias.
\end{abstract}

Palavras-chave: Mastite. Chuvas. Novas infecções. Contagem de células somáticas. 


\section{INTRODUÇÃO}

O sistema agro-industrial do leite, devido a sua importância social, é um dos mais importantes do país. A cadeia do leite compreende mais de 1,3 milhões de propriedades em todo território nacional e, com um PIB de 34,5 bilhões de reais, no ano de 2009 (CEPEA, 2011).

O leite é o produto secretado pela glândula mamária de vacas (ANDRADE, 2006), e é considerado um alimento complexo, que fornece nutrientes e proteção imunológica ao neonato. Na alimentação humana, o leite assume papel importante na dieta, devido ao alto valor nutricional, além de permitir grande variedade de processamentos industriais de diversos produtos e participar da formulação de outros tantos na alimentação humana (JENSEN, 1991).

Atualmente, a qualidade do leite que chega às indústrias de processamento é determinada pela forma com que é produzido e coletado nas unidades de produção de leite (UPL) (PHILPOT; NICKERSON, 2002). Dados do IBGE (2012) revelam que 31\% do leite consumido no Brasil é proveniente do mercado informal, sem nenhum tipo de inspeção e a transmissão de patógenos e toxinas via leite e produtos lácteos representa um risco à saúde do consumidor.

A glândula mamária é um dos órgãos mais diferenciados e metabolicamente ativos do corpo do animal. Sua inflamação denomina-se mastite e pode afetar significativamente a qualidade do leite produzido, diminuindo seu valor nutricional e o aproveitamento para subprodutos causando prejuízos ao produtor e à indústria (LANGONI, 1999), além do risco da transmissão de patógenos infecciosos pelo ato de ingeri-lo sem devido tratamento térmico (BRITO; BRITO, 1997).

As mastites são causadas em sua grande maioria por patógenos bacterianos que podem ser divididos em dois grupos, baseando-se na sua origem: contagiosos e ambientais. Os patógenos contagiosos são aqueles adaptados à sobrevivência no interior da glândula mamária e, geralmente, são transmitidos no momento do manejo da ordenha, destacandose bactérias dos gêneros Staphylococcus, Streptococcus e Corynebacterium. Já os patógenos ambientais como Escherichia coli são melhor descritos como invasores oportunistas do 
úbere, infectando-o através do ambiente sujo ou aliado ao manejo de ordenha (WATTS, 1988).

A doença pode apresentar-se de duas formas: a mastite clinica, que são casos da doença em que existem sinais evidentes da inflamação do úbere e mudança no aspecto do produto secretado, e a sub-clinica, que é assintomática (BRITO; BRITO, 1997). Barbalho e Mota (2001) relatam que a mastite subclínica apresenta maior importância epidemiológica por alastrar-se silenciosamente pelo rebanho sem que sejam percebidas alterações macroscópicas à inspeção do úbere ou de sua secreção. Ambas as formas de apresentação cursam com um aumento na contagem de células somáticas (CCS) do leite, que são provenientes principalmente da corrente sanguínea em resposta à uma inflamação (PHILPOT; NICKERSON, 1991). A CCS é uma importante ferramenta na avaliação do nível de mastite subclínica em uma UPL e da qualidade do leite produzido e, as legislações vigentes estabelecem o limite de 600 mil células/mL de leite como sendo o aceitável e o produtor de leite passa a ser remunerado de acordo com a qualidade do produto (BRASIL, 2011).

O manejo da ordenha desempenha papel fundamental no controle e prevenção da mastite, pois o momento mais importante na disseminação dos agentes e é na ordenha que se estabelecem as principais medidas de controle da mastite (RADOSTITS, 2000). O estado higiênico do úbere, no momento da ordenha, é de significativa importância, pois mostra as condições em que as vacas se encontram fora da sala de ordenha, aonde muitas vezes, chegam com o úbere sujo de barro ou lama (PICOLI, 2008). Neste caso é importante considerar as condições climatológicas do local e a precipitação pluviométrica.

Para Nickerson (2001), vacas mantidas em áreas alagadiças têm mais chances de adquirir mastite por patógenos ambientais. Radostits et al. (1994), comentam sobre a importância das mudanças climáticas de temperatura e umidade do solo, que pode influenciar negativamente nos fatores determinantes para ocorrência de mastite (hospedeiro, agente e meio ambiente). O presente estudo objetivou relacionar a taxa de novas infecções intramamárias com os índices de precipitação pluviométrica. 


\section{MATERIAL E MÉTODOS}

O estudo foi conduzido através do monitoramento mensal de uma propriedade produtora de leite no município de Pelotas-RS durante os meses de maio a dezembro. A propriedade possuía em média 105 vacas em lactação das raças holandês, Jersey, girolando e raças cruzadas. Eram realizadas duas ordenhas diárias com sistema de linha de leite canalizado, com o uso de pré e pós dipping, secagem dos tetos e alimentação dos animais logo após a ordenha em canzil.

Foram realizadas 10 visitas à propriedade, sendo 5 para coleta de amostras para análise bacteriológica e 5 para coleta de amostras para realização da CCS. Em todas as visitas o manejo e os hábitos de higiene na ordenha foram observados. Também a condição de sujeira com que os animais adentravam na sala de ordenha, que foi relacionado com as condições climáticas das épocas específicas das coletas, pois as áreas estavam bem alagadiças e cobertas por barro nas épocas mais chuvosas.

Para as análises de CCS, foram coletadas amostras, em um mesmo recipiente, do leite obtido dos quatro quartos mamários de cada vaca após a ordenha completa e, enviada ao Laboratório de Qualidade do Leite da EMBRAPA-Clima Temperado. Essas amostras, contendo bronopol, foi destinada à determinação da CCS pela técnica de citometria de fluxo em equipamento automatizado.

As amostras de leite para análises bacteriológicas foram coletadas de todos os quartos de todas as vacas em tubos de ensaio de vidro estéreis e adequadamente identificados. Após a coleta, as amostras foram armazenadas em caixas isotérmicas contendo gelo e encaminhadas ao Laboratório de Doenças Infecciosas da Faculdade de Veterinária da Universidade Federal de Pelotas.

Foi preparado meio de cultura ágar-sangue com $5 \%$ de sangue ovino desfibrinado e, $10 \mu \mathrm{L}$ de cada amostra foram semeados nas placas com auxílio de uma alça de platina calibrada para esse volume. As placas foram incubadas em estufa bacteriológica em temperatura de 37으 por 24-48 horas em aerobiose. A caracterização dos agentes isolados nos meios de cultura foi possível através da análise das colônias, por meio das características tintoriais das 
bactérias pela técnica de Gram, e finalmente por meio de provas bioquímicas de acordo com Hogan et al. (1999) e caracterizada segundo Krieg e Holt (1994).

Os valores das precipitações pluviométricas, no período do experimento foram resgatadas através do banco de dados do Laboratório de Agrometeorologia da EMBRAPA-Clima Temperado. Foi utilizada a média das precipitações pluviométricas diárias dos 15 dias anteriores à data de cada coleta.

Foram obtidos os índices de correlação de Pearson através das análises entre o número de novas infecções intra-mamárias por diversos agentes bacterianos isolados e os índices pluviométricos em cada período avaliado. As análises estatísticas foram realizadas utilizando o software Statistix ${ }^{\circledR}$ versão 9.0 .

\section{RESULTADOS E DISCUSSÃO}

A observação do sistema de manejo adotado na propriedade pode fornecer algumas informações valiosas para a discussão desse estudo. Um dos pontos fundamentais foi em relação às condições higiênicas dos animais, especialmente as glândulas mamárias, em períodos chuvosos, quando os animais chegavam à sala de ordenha, vindos do campo, com barro ultrapassando a altura do úbere e dos jarretes. Isso mostra o quanto o ambiente sofreu com a precipitação pluviométrica, criando áreas alagadiças e com muito barro, por onde os animais tinham que caminhar e deitar.

Quanto ao manejo de ordenha, o pré-dipping era realizado, porém muitas vezes o produto não agia por tempo suficiente para eliminar micro-organismos da superfície dos tetos. $O$ pós-dipping era realizado borrifando à distância o produto à base de iodo e glicerina com um borrifador. Esse tipo de procedimento não encobre totalmente a superfície do teto e o produto não tem o efeito esperado (PICOLI et al., 2008).

Das 1917 amostras de leite provenientes dos quartos mamários analisados, obteve-se crescimento microbiano em 1263 amostras e foi possível o isolamento bacteriano em 1071 amostras. Os resultados dos isolamentos bacterianos são demonstrados na Tabela 1. 
Tabela 1. Isolamento bacteriano de quartos mamários de 105 vacas em lactação no período de maio a setembro. Pelotas, RS.

\begin{tabular}{ccccc}
\hline Agente isolado & $\begin{array}{c}\text { Corynebacterium } \\
\text { bovis }\end{array}$ & Staphylococcus sp. & Streptococcus sp. & Total \\
\hline $\begin{array}{c}\text { número de } \\
\text { isolamentos }\end{array}$ & 784 & 260 & 27 & 1071 \\
$\begin{array}{c}\text { \% do total das } \\
\text { amostras }\end{array}$ & 40,9 & 13,6 & 1,4 & 55,9 \\
$\begin{array}{l}\% \text { dos } \\
\text { isolamentos }\end{array}$ & 73,2 & 24,3 & 2,52 & 100 \\
\hline
\end{tabular}

Mendonça et al. (1999) descreve as bactérias do gênero Staphylococcus como os maiores causadores de mastite em rebanhos leiteiros, seguidos por bactérias dos gêneros Corynebacterium e Streptococcus. Barbalho e Mota (2001) ainda quantificam essas prevalências onde isolaram 38,76\% de bactérias do gênero Staphylococcus e 27,91\% de bactérias corineformes do total de isolamentos nos casos estudados.

No Brasil e em outros países, Staphylococcus aureus é apontado como o maior causador de mastites em vacas lactantes (MENDONÇA et al., 1999), porém no presente estudo foi evidenciado maior taxa de prevalência e incidência por parte de Corynebacterium bovis e concorda com Martins et al. (2010), que também encontraram bactérias do gênero Corynebacterium como as mais prevalentes em rebanhos leiteiros.

A elevada prevalência e incidência de $C$. bovis nos leva a aceitar que este agente não deve ser tratado como um patógeno secundário, como alguns autores descreviam no passado (HUXLEY et al., 2003). Em trabalho realizado por Bueno (2003), constatou-se um aumento na presença de Corynebacterium sp. em rebanhos leiteiros do estado de São Paulo quando comparado com trabalhos semelhantes na década de 80.

O grande número de isolamentos de Corynebacterium bovis, mostra seu alto poder contagioso, infectando quartos sadios principalmente no momento da ordenha. Esse fato demonstra também inadequações no manejo higiênico de ordenha, que foram observadas no ato das coletas. O pré e pós-dipping são procedimentos de higiene que, se corretamente realizados, podem impedir essas novas infecções por destruir patógenos presentes na 
superfície e óstio do teto antes da colocação das teteiras e por eliminar patógenos que possam ser transferidos por esta. O C. bovis coloniza o canal do teto, uma área altamente queratinizada de difícil atuação do sistema imune do animal e bem próxima ao esfíncter externo da glândula mamária, o que facilita sua disseminação.

A ocorrência de novas infeç̧ões foi relacionada com a precipitação pluviométrica dos quinze dias imediatamente anteriores à coleta e, a Figura 1 ilustra a relação entre as taxas de novas infecções de cada agente etiológico e a precipitação pluviométrica por período. Entre maio e junho houve 64 novas infecções causadas por C. bovis, 20 por Staphylococcus sp. e 01 por Streptococcus sp., com uma precipitação pluviométrica de $54 \mathrm{~mm}$. Entre junho e julho, houve uma precipitação pluviométrica de $49,8 \mathrm{~mm}$ e 43 novas infecções por $C$. bovis, 36 por Staphylococcus sp. e 05 por Streptococcus sp. Entre julho e agosto, a precipitação pluviométrica foi de 135,2 mm e ocorreram 76 novas infecções por C. bovis, 42 por Staphylococcus sp. e 05 por Streptococcus sp. Já no período entre agosto e setembro, houve 47 novas infecções por C. bovis, 18 por Staphylococcus sp. e 02 por Streptococcus sp e precipitação pluviométrica de 13,2 mm. 


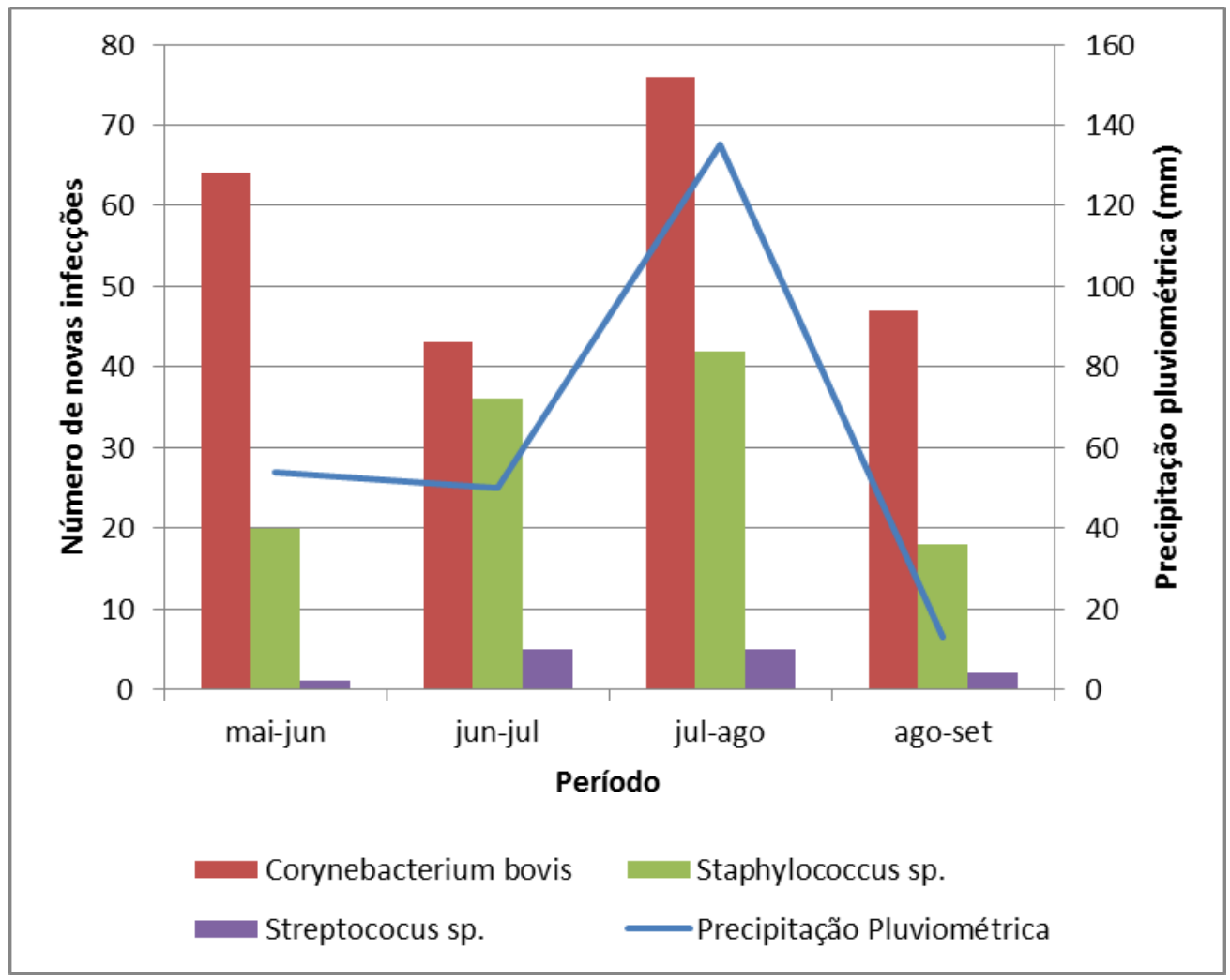

Figura 1. Relação existente entre a precipitação pluviométrica e a taxa de novas infecções por Corynebacterium bovis, Staphylococcus spp. e Streptococcus spp. em um rebanho de 105 vacas em lactação no período de maio a setembro. Pelotas, RS.

Houve alta correlação positiva que vincula a precipitação pluviométrica à ocorrência de novas infecções por $C$. bovis $(r=0,84 ; p=0,074)$, e provavelmente ocorra pelas características do agentes que, frequentemente coloniza o canal do teto e, portanto é facilmente disseminado em um rebanho leiteiro, além de ser altamente contagioso. A alta correlação, porém não foi estatisticamente significativa, segundo o coeficiente de correlação de Pearson obtido. Já a correlação com Staphylococcus spp. apresentou significância estatística $(r=0,81$; $p=0,037)$. Este gênero de patógenos está amplamente distribuídos pelo ambiente e, as espécies capazes de causar infecções intra-mamárias em vacas estão muito disseminados pelo ambiente que estas freqüentam, e os maiores índices de precipitação pluviométrica foi determinante para o surgimento de novas infecções causadas por esse agente. Já a correlação com Streptococcus spp. não foi tão alta $(r=0,58 ; p=0,173)$ nem significativa. Algumas espécies desse gênero não sobrevivem fora do órgão infectado, como é o caso de $S$. agalactiae, porém outras espécies como S. uberis podem ser consideradas ambientais e, 
nesse caso a taxa pluviométrica pode intervir no aparecimento de novas infecções intramamárias.

As CCS dos animais que obtiveram isolamento de apenas um agente bacteriano estão demonstradas na Tabela 2 de acordo com o período observado. Não houve correlação significativa entre os índices do precipitação pluviométrica e a CCS do rebanho $(r=0,48 ; p=$ 0,082). A CCS do rebanho é obtida através do leite coletado diretamente do tanque resfriador, onde fica armazenado o leite de todos os animais. Observa-se pela Tabela 2 que os níveis de CCS diferem de acordo com o agente causador da inflamação e que Staphylococcus spp. cursa com maiores contagens que os outros dois gêneros bacterianos. Isso se deve às características individuais de cada agente, como seus fatores de patogenicidade e virulência. Neste estuda verifica-se que mesmo com as CCS não tão elevadas, as novas infecções ocorreram.

Houve uma significativa correlação positiva entre a precipitação pluviométrica e as CCS dos animais infectados por Staphylococcus spp. $(r=0,79 ; p=0,028)$. Este resultado segue a correlação, também significativa, a precipitação pluviométrica e o número de novas infecções causadas por este agente. Analisando as duas correlações, observa-se que quanto mais chuvoso for o período, maior é o número de novas infeç̧ões intra-mamárias por bactérias do gênero Staphylococcus, que também cursa com maiores contagens de células somáticas.

Tabela 2. Médias das contagens de células somáticas (x 1000) no período de maio a setembro, de acordo com o agente isolado em um rebanho de 105 vacas em lactação.

\begin{tabular}{ccccc}
\hline Agente & mai-jun & jun-jul & jul-ago & ago-set \\
\hline C. bovis & 348,72 & 307,28 & 522,85 & 398,62 \\
Staphylococcus sp & 635,65 & 793,62 & 2256,84 & 578,66 \\
Streptococcus sp & 396,71 & 401,57 & 701,57 & 302,49 \\
Rebanho & 435,76 & 510,43 & 596,47 & 336,96 \\
\hline
\end{tabular}


As correlações com as CCS dos animais acometidos por C. bovis e Streptococcus spp., embora com considerável força, não foram significativas estatisticamente $(r=0,72 ; p=0,095$ e $r=0,54 ; p=0,213)$.

As novas infecções relatadas podem ser de animais sadios que se infectaram ou quartos mamários sadios que foram acometidos. Portanto, o aumento da CCS pode significar que a infecção de um mesmo animal agravou-se ou um novo quarto foi acometido, quanto mais quartos infectados, maior será a CCS desse animal. O aumento do grau de infecção e da CCS é acompanhado pelo aumento do índice de precipitação pluviométrica.

\section{CONCLUSÃO}

De acordo com os resultados obtidos, conclui-se que a precipitação pluviométrica interferiu de forma negativa na produção leiteira deste rebanho, aumentando o número de novas infecções intra-mamárias. Firmou-se também o conceito de que a contagem de células somáticas é uma importante ferramenta que demonstra a realidade do nível de mastite de uma propriedade leiteira.

\section{RATE OF NEW INTRA-MAMMARY INFECTIONS IN DAIRY COWS RELATED TO RAINFALL}

\section{ABSTRACT}

$\mathrm{T}$ he improvement of milk quality has become increasingly important for the society and it is determined mainly by how it is produced. In addition, the microbiological quality of milk is a public health concern and many factors can influence its quality such as the emergence of mastitis which can be related to environmental conditions. This work aimed at listing the new intramammary infections with indexes of rainfall. For both, 1917 samples of milk were collected for microbiological analysis and somatic cells count (SCC) and related to rainfall period. The agents most frequently isolated were Corynebacterium bovis, Staphylococcus spp. and Streptococcus spp. Between the months of may and june there were new infections by $C$. bovis, Staphylococcus spp. and Streptococcus spp., respectively: 64, 20, 01 and rainfall of 54 $\mathrm{mm}$. Between june and july: 43, 36, 05 and 49,8 mm; July and August: 76, 42, 05 and 135 $\mathrm{mm}$; August and September: 47, 18, 02 and 13,2 mm. Correlations between rates of new infections and rainfall were as follows: $C$. bovis $(r=0,84 ; p=0,074)$, Staphylococcus spp. 
$(r=0,81 ; p=0,037)$ and Streptococcus spp. $(r=0,58 ; p=0,173)$. In the period where rainfall was higher, the rate of new infections also increased. Samples submitted to SCC had increased values when the numbers of new infections were higher. According to these findings it is concluded that the rainfall interferes negatively in milk production, increasing the number of new intramammary infections.

Keywords: Mastitis. Rainfall. New infections. Somatic cell count.

\section{LA TASA DE NUEVAS INFECCIONES INTRA-MAMARIAS DE LAS VACAS LECHERAS RELACIONADO CON LA LLUVIA}

\section{RESUMEN}

a mejora en la calidad de la leche ha sido una preocupación constante de la sociedad y se determina principalmente por la forma en que se produce. La microbiología de la -calidad de leche es preocupante para la salud pública y muchos factores pueden influir en esta calidad, la principal es la aparición de la mastitis, la cual puede estar relacionada con las condiciones ambientales tales como la lluvia. Este estudio tuvo como objetivo relacionar la tasa de nuevas infecciones intramamarias con niveles de precipitación. Para ello, se recogieron 1917 muestras de leche para análisis microbiológico y recuento de células somáticas (SCC) que se relaciona con la época de lluvias. Los agentes más aislados fueron Corynebacterium bovis, Staphylococcus spp. y Streptococcus spp. Entre los meses de mayo a junio hubo nuevas infecciones por $C$. bovis, Staphylococcus spp. y Streptococcus spp, respectivamente: 64, 20, 01 y $54 \mathrm{~mm}$ de lluvia. Entre junio y julio: 43, 36, 05 y 49,8 mm. Julio-Agosto: 76, 42, 05 y 135mm. Agosto-Septiembre: 47, 18, 02 y 13.2mm. Las correlaciones entre la tasa de nuevas infecciones y la tasa de precipitación fueron los siguientes: $C$. bovis $(r=0,84 ; p=0,074)$, Staphylococcus spp. $(r=0,81 ; p=0,037)$ y Streptococcus spp. $(r=0,58 ; p=0,173)$. En el período donde la precipitación fue mayor, la tasa de nuevas infecciones también se aumentó. Las CCS aumentaron su valor cuando el número de nuevas infecciones aumentó. Con estos resultados, se concluye que la lluvia interfiere negativamente en la producción de leche, lo que aumenta el número de nuevas infecciones intramamarias.

Palabras clave: Mastitis. Lluvia. Nuevas infecciones. Recuento de células somáticas. 


\section{REFERÊNCIAS}

ANDRADE, E. C. B. Análise de alimentos: uma visão química da nutrição. São Paulo: Varela, 2006.

BARBALHO, T. C. F.; MOTA, R. A. Isolamento de agentes bacterianos envolvidos em mastite subclínica bovina no estado de Pernambuco. Revista Brasileira de Saúde e Produção Animal, v. 2, p. 31-36, 2001

BRASIL. Instrução Normativa n. 62 de 29 de dezembro de 2011. Alteração do caput da Instrução Normativa MAPA n51, de 18 de setembro de 2002. Diário Oficial da União (da República Federativa do Brasil), Brasília, 29 dez. 2011.

BRITO, J. R. F.; BRITO, M. A. V. P. Programas de Controle das Mastites Causadas por Microorganismos Contagiosos e do Meio Ambiente. 1.ed. Minas Gerais: Embrapa, 1997, p. 7-25.

BUENO, V. F. F. Etiologia e suscetibilidade a antimicrobianos dos agentes da mastite bovina isolados na região de Pirassununga, SP, Brasil. Revista de Patologia Tropical, v. 32, n. 1, p. 33-44, 2003.

CENTRO DE ESTUDOS AVANÇADOS EM ECONOMIA APLICADA - CEPEA/USP. Desenvolvimento metodológico e cálculo do PIB das cadeias produtivas do algodão, canade-açúcar, soja, pecuária de corte e leite no Brasil. Piracicaba, 2011. Disponível em: <http://www.cepea.esalq.usp.br/pibpec/PIB_Cadeias_relatorio2009_10.pdf>. Acesso em: 18 abr. 2013.

DINGWELL, R.T.; LESLIE, K.E;, SCHUKKEN Y.H.; SARGEANT, J.M.; TIMMS, L.L.; DUFFIELD, T.F.; KEEFE, G.P.; KELTON, D.F.; LISSEMORE, K.D.; CONKLIN, J. Association of cow and quarterlevel factors at drying-off with new intramammary infections during the dry period. Preventive Veterinary Medicine, v. 63, p.75-89, 2004.

HOGAN, J.S; GONZALEZ, R.N; HARMON, R.J; NIKERSON, S.P; PANKEY, J.W; SMITH, K.L. Laboratory Handbook on Bovine Mastitis. National MastitisCouncil, Inc., Medison, 1999. $222 p$.

HUXLEY, J.N; GREEN, M.J.; BRADLEY, A.J. Corynebacterium bovis - friend or foe? Proceedings of the British Mastitis Conference Garstang, 2003, p. 23-34 Disponível em: <http://www.cabi.org/cabdirect/FullTextPDF/2005/20053159771.pdf >. Acesso em: 15 jun. 2012.

INSTITUTO BRASILEIRO DE GEOGRAFIA E ESTATÍ́STICA - IBGE. Pesquisa trimestral do leite. Rio de Janeiro, 2012. 
JENSEN, R.G.; FERRIS, A.M.; LAMMI-KEEFE, C. Symposium: milk fat - composition, function and potential for change. Journal of Dairy Science, v.74, p.3228-3243, 1991.

KRIEG, N.R.; HOLT, J.C. Bergey's manual os systematic bacteriology. 9ed. Baltimore: Willians\& Wilkins, 1994. 1268p.

LANGONI, H. Complexidade etiológica na mastite bovina In: ENCONTRO DE PESQUISADORES EM MASTITES, 1999. Botucatu, SP. Anais... Botucatu, 1999, p.3-18.

MARTINS, R.P.; SILVA, J.A.G.; NAKAZATO, L.;DUTRA, V.; ALMEIDA FILHO, E.S.A. Prevalência e etiologia infecciosa da mastite bovina na microrregião de Cuiabá, MT. Ciência Animal Brasileira, Goiânia, v. 11, n. 1, p. 181-187, jan./mar. 2010

MENDONÇA, C. L.; FIORAVANT, M. C. S.; SILVA, J. A. B. A. Etiologia da Mamite Bovina. Veterinária Notícias. v. 5, n. 1, p. 107-118, 1999.

NICKERSON, S.C. Mastitis control in replacement heifers, 2001. Disponível em:<http://www.wcds.ca/proc/1996/wcd96389.htm>. Acesso em: 04 jun. 2012.

PHILPOT, W.N.; NICKERSON, S.C. Mastitis: Counter Attack. Naperville: Babson Bros, 1991, p. 150.

PHILPOT, N.W.; NICKERSON, S.C. Vencendo a luta contra a mastite. Ed. Westfalia Landtechnik do Brasil, 2002.

PICOLI, T.; SCHMITT, B.; SCHNEIDER, J.R.; ZANI, J.L. Práticas de manejo e ocorrência de Corynebacterium bovis em propriedades leiteiras no município de Pelotas-RS. In: 350 Congresso Brasileiro de Medicina Veterinária. Anais... Gramado/RS, 2008.

RADOSTITS, O.M., LESLIE, K.E., FETROW, J. Herd health: food animal production medicine. 2.ed. Philadelphia: Saunders, 1994. p. 229-276.

RADOSTITS, O.M; GAY, C.C; BLOOD, W.C; HEMCHELIFF, K.W. Clínica Veterinária - Um tratado de doenças dos Bovinos, Ovinos, Suínos, Caprinos e Eqüinos, Rio de Janeiro: Guanabara Koogan, p. 541-62, 2000.

WATTS, J. L. Etiological agents of bovine mastitis. Veterinary Microbiology, v. 16, p. 41-66, 1988.

Autor para correspondência: Tony Picoli - Universidade Federal de Pelotas. Campus Universitário Capão do Leão, CEP. 354, CEP 96010-900. E-mail:picolivet@gmail.com 